\title{
Materials Development for Hypersonic Flight Vehicles
}

\author{
David E. Glass ${ }^{1}$ \\ NASA Langley Research Center, Hampton, VA 23693 \\ Ray Dirling ${ }^{2}$ \\ SAIC, Fountain Valley, CA 92708 \\ Harold Croop ${ }^{3}$ \\ AFRL, Wright Patterson Air Force Base, OH 45433-7402 \\ and \\ Timothy J. Fry ${ }^{4}$ and Geoffrey J. Frank ${ }^{5}$ \\ University of Dayton Research Institute, Dayton, OH 45469-0110
}

The DARPA/Air Force Falcon program is planning to flight test several hypersonic technology vehicles (HTV) in the next several years. A Materials Integrated Product Team (MIPT) was formed to lead the development of key thermal protection system (TPS) and hot structures technologies. The technologies being addressed by the MIPT are in the following areas: 1) less than $3000^{\circ} \mathrm{F}$ leading edges, 2) greater than $3000^{\circ} \mathrm{F}$ refractory composite materials, 3) high temperature multi-layer insulation, 4) acreage TPS, and 5) hightemperature seals. Technologies being developed in each of these areas are discussed in this paper.

\section{Acronyms}

$\begin{array}{ll}\text { AFRL } & \text { Air Force Research Laboratory } \\ \text { ATI } & =\text { Albany International Techniweave } \\ \text { C-CAT } & =\text { Carbon-Carbon Advanced Technologies } \\ \text { CMC } & =\text { ceramic matrix composite } \\ \text { CVD } & =\text { chemical vapor deposition } \\ \text { CVI } & =\text { chemical vapor infiltration } \\ \text { DARPA } & =\text { Defense Advanced Research Projects Agency } \\ \text { GRC } & =\text { Glenn Research Center } \\ \text { HCV } & =\text { Hypersonic Cruise Vehicle } \\ \text { HHT } & =\text { High Heat Treat } \\ \text { HS } & =\text { Harness satin } \\ \text { HTMLI } & =\text { High Temperature Multi-Layer Insulation } \\ \text { HTMITAS } & =\text { High Temperature Multi-Layer Insulation Thermal Analysis Software } \\ \text { HTV } & =\text { Hypersonic Technology Vehicle } \\ \text { ILS } & =\text { interlaminar shear } \\ \text { LHMEL } & =\text { Laser Hardened Material Evaluation Laboratory }\end{array}$

\footnotetext{
${ }^{1}$ Falcon MIPT Lead, Structural Mechanics and Concepts Branch, MS 190, AIAA Associate Fellow

2 Manager, Spacecraft and Missile Systems, Technology Solutions Division, 17330 Brookhurst St., Suite 330, AIAA Member

3 Thermal Structures Consultant, Anteon Corporation, 2790 D Street Bldg 65

${ }_{5}^{4} \mathrm{Sr}$. Research Engineer, Aerospace Mechanics Division, 300 College Park, M/S 0110

${ }^{5}$ Sr. Research Engineer, Aerospace Mechanics Division, 300 College Park, M/S 0110, AIAA Senior Member
}

The use of trademarks or names of manufacturers in this paper is for accurate reporting and does not constitute an official endorsement, either expressed or implied, of such products or manufacturers by the National Aeronautics and Space Administration, Defense Advanced Research Projects Agency, or the U.S. Air Force. 


$\begin{array}{ll}\text { LM } & =\text { Lockheed Martin } \\ \text { MIPT } & =\text { Materials Integrated Product Team } \\ \text { MLFI } & =\text { multi-layer foil insulation } \\ \text { MLOP } & =\text { Multiparameter Mission Simulation Facility } \\ \text { MMSF } & =\text { multi-parameter test } \\ \text { MPT } & =\text { Materials Research \& Design, Inc. } \\ \text { MR\&D } & =\text { National AeroSpace Plane } \\ \text { NASP } & =\text { Pre ceramic polymer } \\ \text { PCP } & =\text { Physical Sciences, Inc } \\ \text { PSI } & =\text { physical vapor deposition } \\ \text { PVD } & =\text { Refractory Composites, Inc. } \\ \text { PWR } & =\text { Room temperature } \\ \text { RCI } & =\text { Small Launch Vehicle } \\ \text { RT } & =\text { S.D. Miller Associates Research Foundation } \\ \text { SLV } & =\text { Tetraethylorthosilicate } \\ \text { SMARF } & =\text { Thermal Protection Systems } \\ \text { SRI } & =\text { University of Dayton Research Institute } \\ \text { TEOS } & =\text { vacuum plasma spraying } \\ \text { TPS } & \end{array}$

\section{Introduction}

$\mathrm{T}$ HE Defense Advanced Research Projects Agency (DARPA) and the United States Air Force have initiated the Falcon program to pursue the dual objectives of advancing hypersonic flight technology and developing a new low-cost space launch system. The Falcon program consists of two tasks. Task 1, the Small Launch Vehicle (SLV), has a primary objective of developing a launch vehicle capable of placing a 1,000 pound satellite into a 100 nautical mile, due east orbit when launched from Cape Canaveral Air Force Base. Task 2, the Hypersonic Technology Vehicle (HTV), will develop and flight test a number of key enabling technologies for hypersonic flight. The goal is a reusable hypersonic cruise vehicle (HCV) capable of global reach at a cruise speed approaching Mach 10.

As part of the Falcon program, a series of demonstration vehicles, referred to as HTV-1, HTV-2, and HTV-3, are being developed. These vehicles will demonstrate the technologies required for the HCV. HTV-1 and HTV-2 are flight test-beds that will demonstrate enabling technologies for future hypersonic reentry operational systems. HTV3 is a flight test-bed that will demonstrate enabling technologies for a future hypersonic cruise vehicle.

Though the HTV-1 is assumed to utilize state-of-the-art materials, both the HTV-2 and HTV-3 will require materials development to meet their requirements for thermal loading. DARPA has established a Materials Integrated Product Team (MIPT) to work with Lockheed Martin on Task 2 in the development of materials for HTV-2, HTV-3, and HCV. The focus of the MIPT is on materials development for TPS and hot structures. Materials for propulsion components and for cryogenic tanks are not currently being considered by the MIPT. The immediate goal of the MIPT efforts is use on HTV-2 and/or HTV-3. Toward this end, Figure 1 illustrates the technical challenges on HTV-2 and HTV-3.

The long use time at high temperatures for the HTV-2, and the added requirement of multiple cycles for the $\mathrm{HCV}$, led the MIPT to select five technical areas for materials development. These five technology areas were identified as ones that are critical for achieving HCV operational objectives and in need of maturation to lower the Falcon program risk. The five areas are: 1) leading edges at use temperatures of less than $3000^{\circ} \mathrm{F}, 2$ ) fiber reinforced composites with a use temperature of greater than $3000^{\circ} \mathrm{F}, 3$ ) high temperature multi-layer insulation, 4) acreage thermal protection systems, and 5) high-temperature seals. Development aspects in these five areas are discussed in this paper, including discussions of what has worked and areas that remain as challenges. This work has been funded by DARPA. Except for high-temperature seals development performed at NASA Glenn Research Center, the work has been performed under subcontracts administered by the University of Dayton Research Institute (UDRI). 


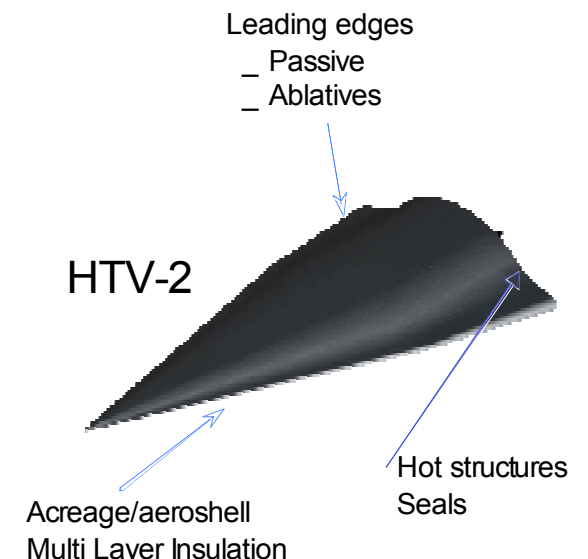

Multi Layer Insulation

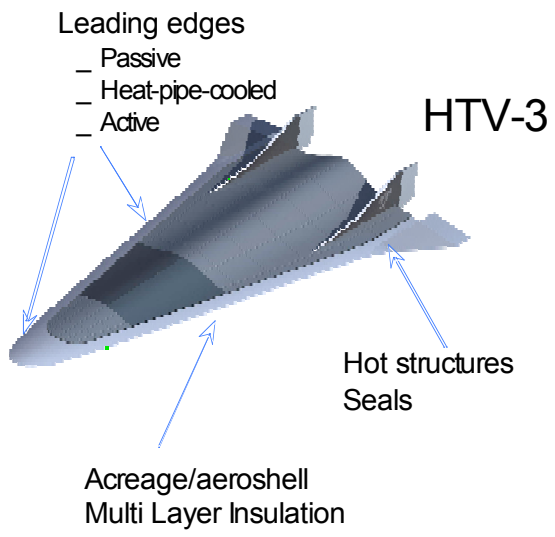

Figure 1. Materials on HTV-2 and HTV-3 requiring development.

\section{Description of Materials Development}

A number of material developers were selected for funding under the MIPT's guidance to develop materials and designs to support the Falcon program. Their activities have been integrated with Lockheed Martin's design and development efforts. These contractors developed coupon-level systems that were tested under conditions expected for HTV and HCV systems. Work in each of the five technology areas is described below, broken into sections describing the work of each of the material developers.

\section{A. Below $3000^{\circ} \mathrm{F}$ Leading Edge Materials}

The objective of the $3000^{\circ} \mathrm{F}$ Leading Edge task is the improvement of advanced oxidation-protection systems for refractory composite materials for a nominal $3000^{\circ} \mathrm{F}$ temperature regime with the emphasis on multiple mission lifetime capability. This effort is focused on improving existing material systems rather than creating/designing totally new material systems. The ultimate goal for the oxidation-protection system is to provide multiple mission $(>50)$ lifetime capability for leading-edge and hot structure components in a hypersonic cruise environment. The immediate goal of the oxidation-protection system is to provide single mission capability for leading-edge and hot structure components in a hypersonic maneuvering environment.

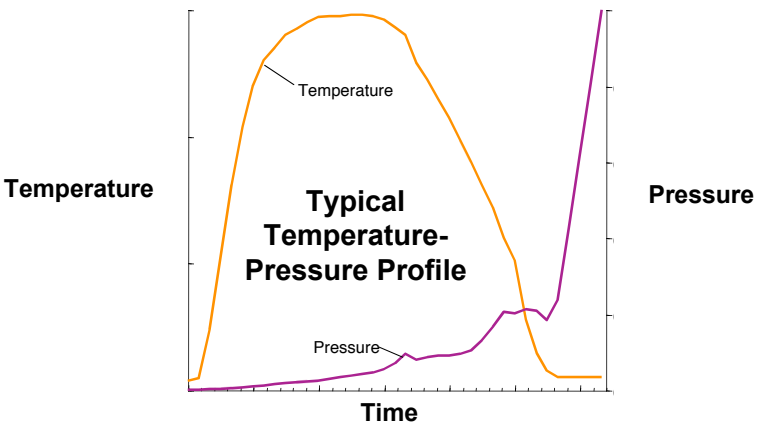

Figure. 2 Typical temperature/pressure profile in the MMSF. 
Two contractors were selected to improve coatings for carbon-carbon (C-C) leading edges. One contractor was Carbon-Carbon Advanced Technologies, Inc. (C-CAT) of Fort Worth, TX and the other contractor was Pratt \& Whitney Rocketdyne (PWR) of West Palm Beach, FL. Both contractors adapted coating processes that have been used on other high-temperature systems.

Evaluation of the materials being developed is being performed both at Southern Research Institute (SRI) and NASA Langley Research Center. SRI is determining tension and compression strength (RT to $3000^{\circ} \mathrm{F}$, with modulus), interlaminar strength (RT to $3000^{\circ} \mathrm{F}$ ), thermal expansion (RT to $3000^{\circ} \mathrm{F}$ ), and thermal conductivity (RT to $1800^{\circ} \mathrm{F}$ ). Microstructure both before and after testing is also being evaluated. In addition to the material properties described above, 1 in. x 4 in. coated specimens are being testing in the Multiparameter Mission Simulation Facility (MMSF) at NASA Langley Research Center. The MMSF permits the test coupons to be evaluated under elevated temperatures, reduced air pressure, and mechanical load simultaneously, thus simulating a mission profile (see Figure. 2). Arc jet testing of coupons will follow after a downselect and further development.

\section{C-CAT Materials ${ }^{l}$}

C-CAT manufactured panels from which test coupons could be obtained using a T300-1K 4HS carbon fiber impregnated with phenolic resin with a quasi-isotropic lay-up sequence. The panels were pyrolyzed and densified to an ACC-6 condition, coated with a $\mathrm{SiC}$ conversion coating, and coated with a $\mathrm{Si}_{3} \mathrm{~N}_{4}$ or $\mathrm{SiC}$ pre-ceramic polymer (PCP). Tetraethylorthosilicate (TEOS) impregnation and the application of Type A sealant followed the application of the PCP. All samples were glassed using a pre-fire, which pre-forms glass from the Type A sealant to provide further protection.

The primary modification to the C-CAT standard processes for components in the $3,000^{\circ} \mathrm{F}$ temperature range was the application of the PCP. This modification was required because the Type A sealant functions by forming a glass above $1,500^{\circ} \mathrm{F}$ in the presence of $\mathrm{O}_{2}$ and flows across the surface to form an oxidation barrier. However, the low pressure, low-oxygen environment anticipated for these leading edges means that the Type A sealant may not have sufficient oxygen to form an effective barrier.

Mechanical property testing was conducted at Southern Research Institute (SRI) and NASA Langley Research Center (Langley). The focus of the SRI mechanical testing was to determine properties both at room temperature and at $3000^{\circ} \mathrm{F}$. The purpose of the testing at Langley was to determine residual mechanical properties after cycling test specimens from 1 to 10 Falcon specific re-entry cycles.

\section{PWR Materials ${ }^{2}$}

PWR utilized an inhibited HITCO C-C substrate and applied a $\mathrm{Si}_{3} \mathrm{~N}_{4}$ coating via chemical vapor deposition (CVD). CC137EL is a T300 fabric-based inhibited C-C and has a long history of use for structural applications. The lay-up was quasi-isotropic using a T300 8HS weave fabric.

HITCO CC137EL uses an oxidation inhibitor that serves to bridge the temperature range from $750^{\circ} \mathrm{F}$, which is the limit for $\mathrm{C}-\mathrm{C}$ materials without any oxidation protection, and the coating deposition temperature. Boria has a boiling point of $3380^{\circ} \mathrm{F}$ and it should not volatilize/expand under the coating at $3250^{\circ} \mathrm{F}$ service temperature; however, hot boria is a good solvent and could attack the $\mathrm{Si}_{3} \mathrm{~N}_{4}$ coating. CC137EL was selected over other boroninhibited materials to provide sufficient oxidation resistance while minimizing coating reaction issues.

Prior to $\mathrm{Si}_{3} \mathrm{~N}_{4}$ coating, the surface of the $\mathrm{C}-\mathrm{C}$ was converted to porous $\mathrm{SiC}$ by the pack coating process. The porous $\mathrm{SiC}$ layer provides improved adhesion of the $\mathrm{Si}_{3} \mathrm{~N}_{4}$ coating. Pack coating was performed by Synterials Inc. and resulted in a porous $\mathrm{SiC}$ layer. Synterials subsequently deposited the $\mathrm{Si}_{3} \mathrm{~N}_{4}$ coating onto the CC137EL substrates by CVD.

The mechanical and thermal properties of uncoated and coated CC137EL were measured by SRI. In general, the properties are lower than those typically measured on CC137EL, even for uncoated specimens.

It is likely that the mechanical properties are degraded from the values typically reported by HITCO for this material due to a combination of factors, including:

- Tests were performed perpendicular to the fiber warp direction (typical data is acquired parallel to the warp direction);

- Surface fibers were damaged during pack coating; and,

- A non-standard densification process was used, possibly resulting in less matrix deposited in the interior of the panels.

Tests were stopped whenever a sample had a mass loss of more than $75 \mathrm{~g} / \mathrm{m}^{2}$. This restriction caused most of the tests at temperatures above $2500^{\circ} \mathrm{F}$ to be stopped before the desired number of cycles (usually 10 ) had been 
achieved. The excessive mass loss was due to a combination of coating much thinner than the target value, wire marks where molybdenum wire was used to support the samples during coating, and variability in the grain structure of the coating.

Because of the poor performance of the $\mathrm{Si}_{3} \mathrm{~N}_{4}$ coated CC137EL in the NASA Langley cyclic rig testing, Synterials made processing changes to improve the coating. It is expected that C-C materials with this improved coating will have much better residual strength and greatly reduced mass loss after thermal cycling.

The test data obtained on the specimens described here did not meet the targets for residual strength and mass loss. However, the material samples produced using the modified manufacturing methods developed by C-CAT and PWR after submitting samples for thermal and mechanical testing are very encouraging. These samples indicate that many of the manufacturing issues have been solved. Materials made using the modified methods will be tested in the next development phase, which will include requirements for manufacture of more complex shapes.

\section{B. Above $3000^{\circ} \mathrm{F}$ Refractory Composite}

The objective of this task is the improvement of advanced oxidation-protection systems for refractory composite materials for a nominal $3600^{\circ} \mathrm{F}$ temperature regime with the emphasis on multiple mission lifetime capability. Due to the limited funding and the desire for an effort that will lead to application of a TPS on flight vehicles in the intermediate term, the current work was directed to improving existing material systems rather than creating/designing totally new material systems. The ultimate goal for the oxidation-protection system is to provide multiple mission $(>10)$ lifetime capability for leading-edge components in a high heat flux hypersonic cruise environment. The focus is on development of advanced oxidation-protection system concepts (encompassing substrate, substrate inhibitors, and coatings) for fiber reinforced refractory composite matrix materials.

Following is a discussion of the development of high temperature refractory composites for applications at temperatures greater than $3000^{\circ} \mathrm{F}$ by two contractors: ATK and Physical Sciences, Inc. (PSI). ATK evaluated three different oxidation protection coatings on two different substrates. PSI used a PCP to fabricate a multiuse, hightemperature composite.

Evaluation of the materials being developed is similar to those in the Below $3000^{\circ} \mathrm{F}$ Leading Edge task except for testing to $3600^{\circ} \mathrm{F}$ rather than $3000^{\circ} \mathrm{F}$. In addition, the multi-parameter testing to $3600^{\circ} \mathrm{F}$ was done at SRI rather than NASA Langley.

\section{ATK Materials $^{3}$}

ATK chose two materials for substrate fabrication, based on work ATK has been doing in development of lower cost two-dimensional (2D) C-C materials. The first material, High Heat Treat (HHT) T300, is a continuous, polyacrylonitrile (PAN) based woven fabric, utilizing a $3 \mathrm{k}$ tow woven into a five harness satin (5HS), balanced, $24 \times 24$, fabric. The fabric was heat treated prior to impregnation to increase bond strength between the fiber and the matrix..

The second material was MX4830HS, where the reinforcement was woven into a 5HS fabric using stretch broken, 3k, PAN-based yarn. The resin system was a high purity phenolic.

A 16-ply quasi-isotropic lay-up was used for both materials, resulting in nominally 0.25 -in-thick panels. Conversion to C-C was performed using ATK's conventional liquid pitch carbonization (LPI) process running in parallel with standard production parts.

Mechanical property tests were performed at SRI on materials that did not have oxidation protection coatings. These properties, measured without any thermal cycling of the materials, are typical of these materials except for the interlaminar shear strength (ILS), which is about half the historical value for similar 2-D C-C materials. The low ILS may be due to the quasi-isotropic lay-up, which, unlike most materials previously tested for ATK, did not use warpaligned fibers.

Two oxidation protection systems were evaluated by ATK; these are a) a multi-layer oxidation protection (MLOP) system of Ir and modified $\mathrm{HfO}_{2}$, and b) a pre-ceramic polymer (PCP) impregnation and conversion.

The MLOP was applied using vacuum plasma spraying (VPS), applied by Plasma Processes, Inc. VPS was used to apply Hafnium, which was then converted into its carbide. This formed a carbide "bond coat", which was followed by a diffusion barrier (Iridium) and finished with a higher emissivity coating.

For the PCP coating, ATK used a PCP that converts upon heat treatment into a mixed phased SiC. The SiC can be made more or less crystalline by proper selection of heat treatment temperatures and dwell times. Since the C-C was graphitized at about $3,600^{\circ} \mathrm{F}$, ATK did not heat-treat above this temperature after impregnating with the PCP. 
The actual SiC yield from the PCP is relatively low and necessitated multiple heat treatment cycles to provide adequate protection of the $\mathrm{C}-\mathrm{C}$.

Testing of the substrate/coating systems was conducted at SRI in a newly fabricated multi-parameter test (MPT) facility that can be programmed and controlled to simulate four aspects of a re-entry vehicle trajectory: temperature, absolute pressure, gas composition and flight duration. SRI utilized a flight trajectory provided by LM, the prime contractor for the hypersonics part of the Falcon program, for its MPT conditions. This thermal loading does not create any shear loads, shape factors, pressure loads or thermo-structural aspects of a real flight.

\section{PSI Materials}

PSI utilized a pre-ceramic polymer to fabricate multiple compositions of a carbon fiber reinforced CMC. Mixed refractory matrices form protective surfaces that impart oxidation resistance at temperature, eg. $\mathrm{R}=\mathrm{Ta}$, as shown in Figure 3. PSI utilized high-temperature testing at the Laser Hardened Material Evaluation Laboratory (LHMEL) facility at the AFRL in Dayton, OH to help optimize the materials for different temperature regimes. The PSI material was also tested at NASA Langley and SRI. Like other materials tested, the PSI materials did not provide the multiple cycle life desired by the Falcon program.

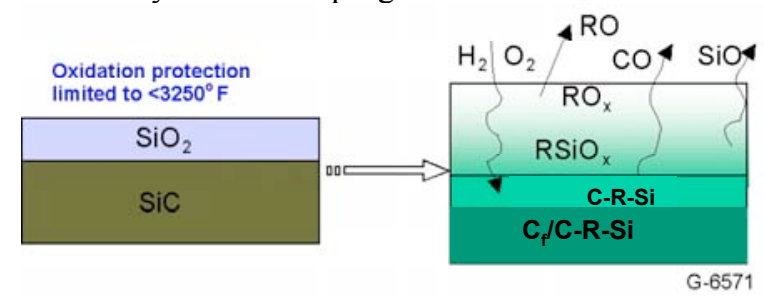

Figure 3. Refractory element additions, e.g., $R=$ Ta, are used to enable oxidation resistance of the UHT composites.

\section{High Temperature Multi-Layer Insulation}

The objective of the High Temperature Multi-Layer Insulation (HTMLI) task is the development of low volume, lightweight multi-layer foil insulation (MLFI) that have maximum temperature capabilities up to $3000^{\circ} \mathrm{F}$ for future reusable and non-reusable hypersonic vehicles. To achieve this temperature, improved refractory fibers and/or low emissivity films are required. The system should be capable of operating in a low pressure air environment without oxidation or substantial increase in the film emissivity. This work was focused on application of a TPS to flight vehicles in the intermediate term by improving existing insulation systems rather than creating/designing totally new approaches. The ultimate goal for the HTMLI is to provide multiple mission $(>50)$ lifetime capability in a hypersonic cruise environment.

The primary application for this insulation is in acreage TPS which makes it essential that the system be affordable. The immediate goal of the HTMLI is to provide single mission capability for TPS components for the HTV-2. In addition, there is a desire to further reduce the thermal conductivity and increase the temperature capability of existing insulation with the goal of demonstrating insulation with a nominal maximum reusable temperature of $3000^{\circ} \mathrm{F}$. The focus is on development of advanced lightweight refractory materials and low emissivity films with affordable manufacturing techniques. Water intrusion, oxidation, and increased thermal conductivity of the insulation due to compression of the insulation need to be minimized or eliminated.

Two contractors were selected to further develop the high temperature multi-layer insulation. One HTMLI contractor was Refractory Composites, Inc. (RCI) of Glen Bernie, MD. RCI utilized metallic foils separated by fibrous insulation and sealed in a metallic "bag" to protect the MLI from oxidation. The other contractor was Steve Miller Associates Research Foundation (SMARF). SMARF modified an existing $1800^{\circ} \mathrm{F}$ MLI design to extend the temperature capability to $3000^{\circ} \mathrm{F}$ via the substitution of higher temperature materials.

Both contractors developed advanced MLFI systems. MLFI consists of thin metallic foils separated by ceramic layers and disposed in a manner to minimize radiation, conduction and convection heat transfer through the insulation from hot face to cold face. MLFI works best at elevated temperatures at which radiation heat transfer is a significant mode for thermal energy transmission. At temperatures on the order of $1200^{\circ} \mathrm{F}$, a transition to an efficient conventional fibrous insulation is appropriate.

\section{$R C I M L F I^{4}$}

Mulit-Layer Foil Insulation (MLFI) developed by RCI consisted of alternating layers of thin metallic foils separated by ceramic layers and disposed in a manner to minimize radiation, conduction and convection heat 
transfer through the insulation from hot face to cold face. The assembly of layers was enclosed in a hermetically sealed outer envelope with vacuum inside to reduce the convection heat transfer to a minimum.

Designs were optimized using an analysis approach that involved a stepwise heat transfer calculation of the steady state thermal gradient through candidate MLFI designs. This analytical treatment accounted for temperature dependent thermal properties including emissivity and thermal conductivity of the MLFI constituents. An ideal MLFI would have a hermetically sealed outer envelope with vacuum inside to reduce the convection heat transfer to minimum. However, fabricating this envelope was a significant challenge. The development of the envelope required precision foil cutting, folding, and thin foil welding. Early in the program, several laser and electron beam welding subcontractors performed welding trials on 0.003 in. foils, mostly with unsatisfactory results. Typical defects were incomplete fusion or melt-through holes. Using a proprietary technology that utilizes laser and electron beam technologies, Belt Technologies Inc. was able to weld the thin metal sheets, as illustrated in Figure 4.

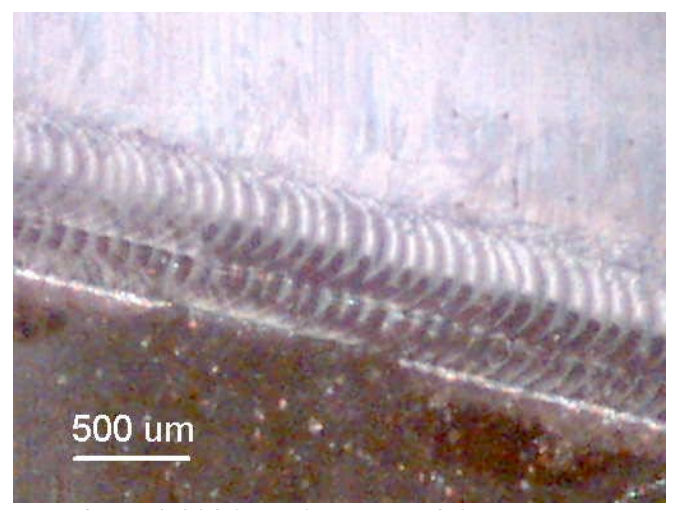

Figure 4. Lap weld of two 0.003 in. thick metal foils by Belt Technology, Inc.

Fabrication of the MLFI hermetic vacuum box was very difficult. The box lid and the base box need to be precisely matched prior to welding. The corners of both the lid box and base box need to be hermetically sealed. Box corner forming trials indicated that the goal of making MLFI boxes hermetic would be beyond the schedule and funds available in this program. As the weld fusion process reaches the tri-corner region (the intersection of two sides and a bottom or top skin), the molten weld pool wicks away from the corner in all three directions leaving a pinhole at the corner. Also, welding distortion proved to be a problem, although dimensional control could be improved through tooling modifications and proper line-up of the lid box and base boxes.

A high temperature precious metal oxidation protection coating was applied to metal foil test coupons using a physical vapor deposition (PVD) technique. Coated samples were sent to the NASA Langley MMSF to test under simulated HTV flight conditions. Due to inadequate pre-coating cleaning and over coating, both thin and thicker oxidation protection layers peeled off the test specimens in the early stages of MPTF testing at $2100^{\circ} \mathrm{F}$ under 0.16 psi atmospheric pressure test condition.

\section{SMARF MLI $I^{5}$}

An $1800^{\circ} \mathrm{F}$ MLI previously developed by SMARF was selected as the initial baseline design. Under this program, alternate materials that could be used at higher temperatures were identified and subjected to initial screening analyses and tests.

A silica-based paper stabilized with an alumina-based adhesive was selected for the reflective layers. Lowemittance coatings using either gold or platinum were identified, and coatings of both materials were tested. Gold coated reflective layers with spacers are shown in Figure 5.

The MLI designs were optimized using the High Temperature Multi-Layer Insulation Thermal Analysis Software (HTMITAS), which predicts MLI performance for transient applications. Refractory fiber improvements that enhanced the radiation exchange between MLI reflective layers to match the use temperature were developed. Gold coated flat reflective layers with Saffil insulation spacers are shown in Figure 6.

Prototype MLI samples, 12 in. x 12 in., that used each of these various materials to its best advantage and in specific locations to meet the mission criteria were fabricated and subsequently tested at Langley. Several of these configurations met the design goal of a maximum backface temperature of $250^{\circ} \mathrm{F}$ after undergoing the temperature/pressure profile. 


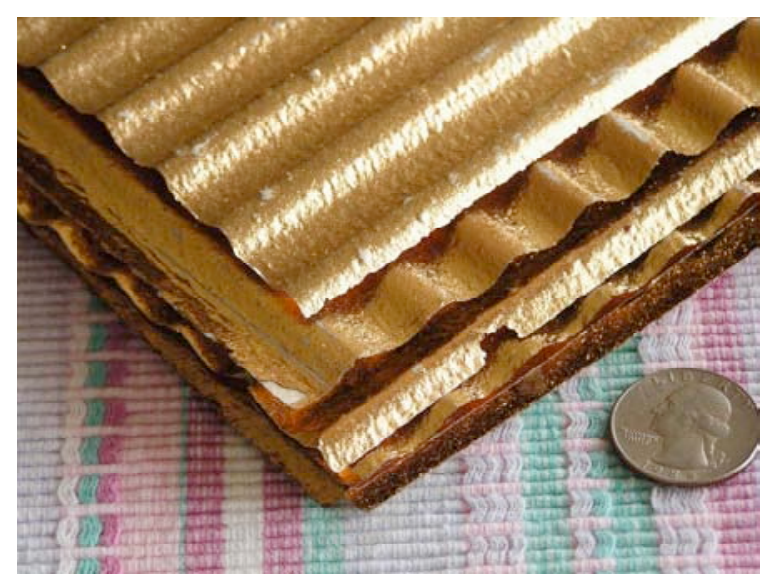

Figure 5. Photograph of MLI reflective layers developed by SMARF.

The test data showed a substantial temperature gradient across the titanium backplate in the plane parallel to the samples. Thermocouples located at the center, at the midpoint between center and the plate edge and at the edge of the backplate showed a large temperature gradient, increasing from center to edge of the plate. After reviewing the body of data, it was surmised that this was due to lateral heat transfer between the MLI sample and the surrounding insulation.

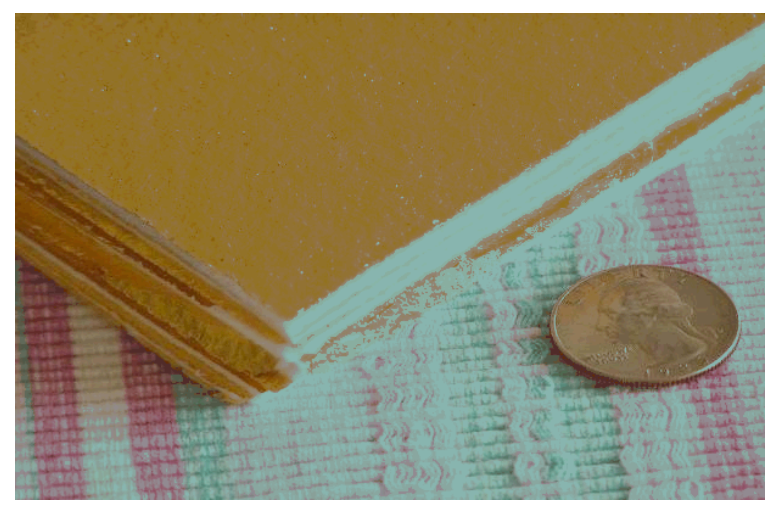

Figure 6. Photograph of MLI flat reflective layers with Saffil spacers developed by SMARF.

A 3-D heat transfer model of the test set up and sample was used to analyze the temperature data to better understand the measured performance of the highly anisotropic MLI. The model was developed with Thermal Desktop ${ }^{\circledR}$ and SINDA/FLUINT. The model indicated that heat flows out of the upper MLI layers, bypassing the MLI stack, and re-entering the titanium plate. The predicted temperatures were in good agreement with the measured temperature variation in the titanium backplate, providing confidence in the numerical predictions of the model.

The heat transfer model was subsequently used to simulate application of the insulation for a Falcon mission. A one-dimensional heat transfer was assumed, which is representative of actual conditions for application of insulation to large areas of a vehicle. According to these predictions, the SMARF MLI tested at Langley would keep the backface temperature of the insulation below that required.

A 5 in. $x 5$ in. sample of MLI was tested at SRI to evaluate effects of pressure and exposure to temperatures as high as $3000^{\circ} \mathrm{F}$. The sample tested showed no damage after six cycles of testing with peak temperatures of 2000 to $3000^{\circ} \mathrm{F}$. Testing of the sample also showed a strong correlation between thermal transmittance and ambient pressure which is consistent with theory used for modeling MLI.

The data measured at Langley and SRI, coupled with the analytical thermal predictions, indicated that the nonevacuated MLI developed by SMARF can survive the environment anticipated for the HTV-2 while limiting the backface temperature to manageable temperatures. 


\section{Acreage Thermal Protection Systems ${ }^{6}$}

The objective of the Acreage Thermal Protection System task is the development of a TPS and an attachment system to join hot aeroshells to cooler internal structures for future reusable and non-reusable hypersonic vehicles. The goal was to determine the largest possible panel size for each candidate TPS shell material. The internal structures are limited to no more than $350^{\circ} \mathrm{F}$. The linear separation between the aeroshell and internal structure, which will be filled with insulation, should be minimized to reduce overall vehicle weight and volume.

To achieve these capabilities, the attachment system must be able to withstand a thermal gradient of several thousand degrees Fahrenheit over a distance of only a few inches; it should have sufficient insulating capability to avoid heat shorting to the underlying cool structure; and, be sufficiently structurally compliant to accommodate differences in thermal expansion between the aeroshell and the internal structure. The attachments must be capable of operating in a low pressure air environment without oxidation.

Drawing Not To Scale

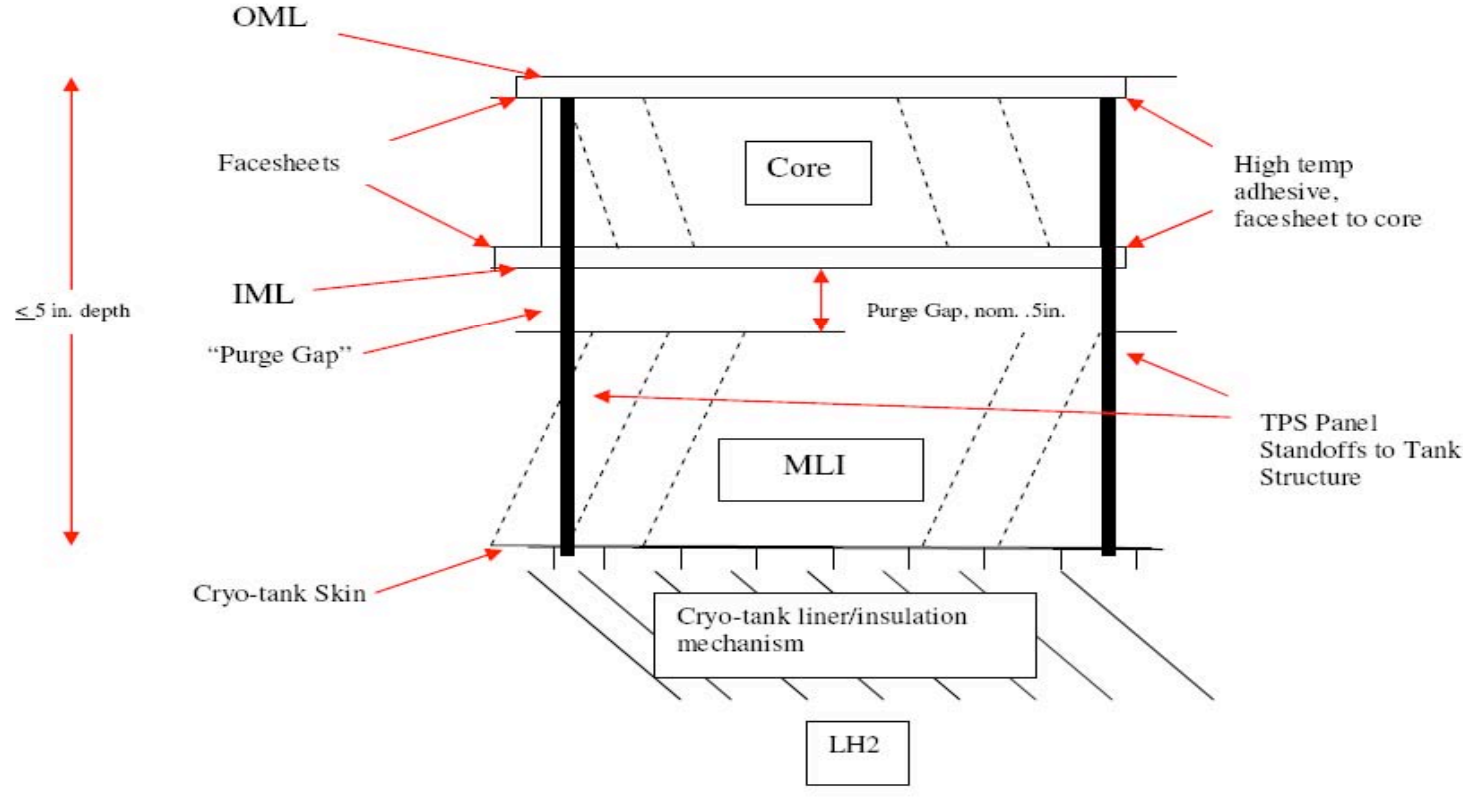

Figure 7. Schematic of concept 1 (with purge gap and standoff attachments).

The goal of this task is application on flight vehicles in the intermediate term. Therefore the current work is directed to improving or leveraging existing aeroshell and attachment systems to the maximum extent possible. The ultimate goal of the integrated aeroshell/structure system is to provide multiple mission $(>50)$ lifetime capability for aeroshells in a hypersonic cruise environment. The immediate goal of the integrated aeroshell/structure system is to provide single mission capability for the HTV.

Only one contractor was selected to develop the required acreage TPS, Materials Research \& Design, Inc. (MR\&D) of Wayne, PA. MR\&D began their effort by validating numerical codes utilizing test data from the thermal acoustic testing of a $\mathrm{C} / \mathrm{SiC}$ TPS panel dating back to the National AeroSpace Plane (NASP) program. Following the code validation, MR\&D designed an acreage TPS that can successfully be integrated with the structure.

MR\&D performed design and analysis work on a thermal protection system (TPS) panel as well as the method to attach the hot aeroshell TPS to the cool internal structure for the acreage regions of a hypersonic cruise vehicle. Research was first performed to become more familiar with previous work done on TPS and attachment designs 
from programs such as NASP and X-33. In the data correlation effort, MR\&D demonstrated an understanding of two different acreage ceramic matrix composite (CMC) TPS panel designs through generation of detailed mathematical models.

In the trade study effort, MR\&D performed thermal, mechanical, and thermal stress analyses on a wide variety of TPS materials and designs to determine the largest panel size able to meet the design requirements. The design evolved from a facesheet-core-facesheet sandwich structure to a rib-stiffened design after fabricators expressed concerns about being able to bond the facesheets and cores together. The rib-stiffened designs were analyzed using both $\mathrm{C} / \mathrm{SiC}$ and $\mathrm{C}-\mathrm{C}$. The designs were optimized to determine the lowest areal weights possible while still maintaining positive margins of safety. There was a goal of 2.0 pounds per square foot (psf) for the areal weight of the TPS panel, including standoffs and attachments. Due to the difference in strengths between $\mathrm{C} / \mathrm{SiC}$ and $\mathrm{C}-\mathrm{C}$, more ribs and thicker parts were needed to obtain positive margins of safety with the $\mathrm{C}-\mathrm{C}$ design. A layer of insulation between the TPS panel and the tank skin surface was required to keep the tank temperature below $350^{\circ} \mathrm{F}$. Insulation sizing was done by performing transient heat transfer analyses using the heat flux environment design requirements. This insulation was also optimized to obtain the lowest possible areal weight.

The goal of the trade study was to determine the largest possible panel size for each candidate TPS shell material. There were a number of design requirements, both thermal and mechanical, that had to be satisfied by the CMC aeroshell design. There were two thermal conditions which were used to size the insulation layer that was necessary between the hot aeroshell and the cool internal structure (tank). In addition to these two thermal conditions, there was also the task of minimizing thermal shorts between the aeroshell and the tank surface and accounting for thermal expansion through thermal stress analyses.

There were two concepts that were considered in this trade study. The first concept, which was the main focus of the study, is shown in Figure 7. This concept consisted of a facesheet-core-facesheet sandwich structure TPS panel attached to the tank structure by standoffs. Below the sandwich structure was a 0.5 in. purge gap and then a layer of insulation, which was directly above the tank skin. The second concept, shown in Figure 8, did not have standoff attachments or a purge gap between the TPS panel and the insulation layer. A very in-depth trade study was performed for the first concept, including a wide variety of candidate materials and ultimately resulting in final designs. For the second concept, material strength requirements for adhesives and insulation layers were obtained from the analyses.

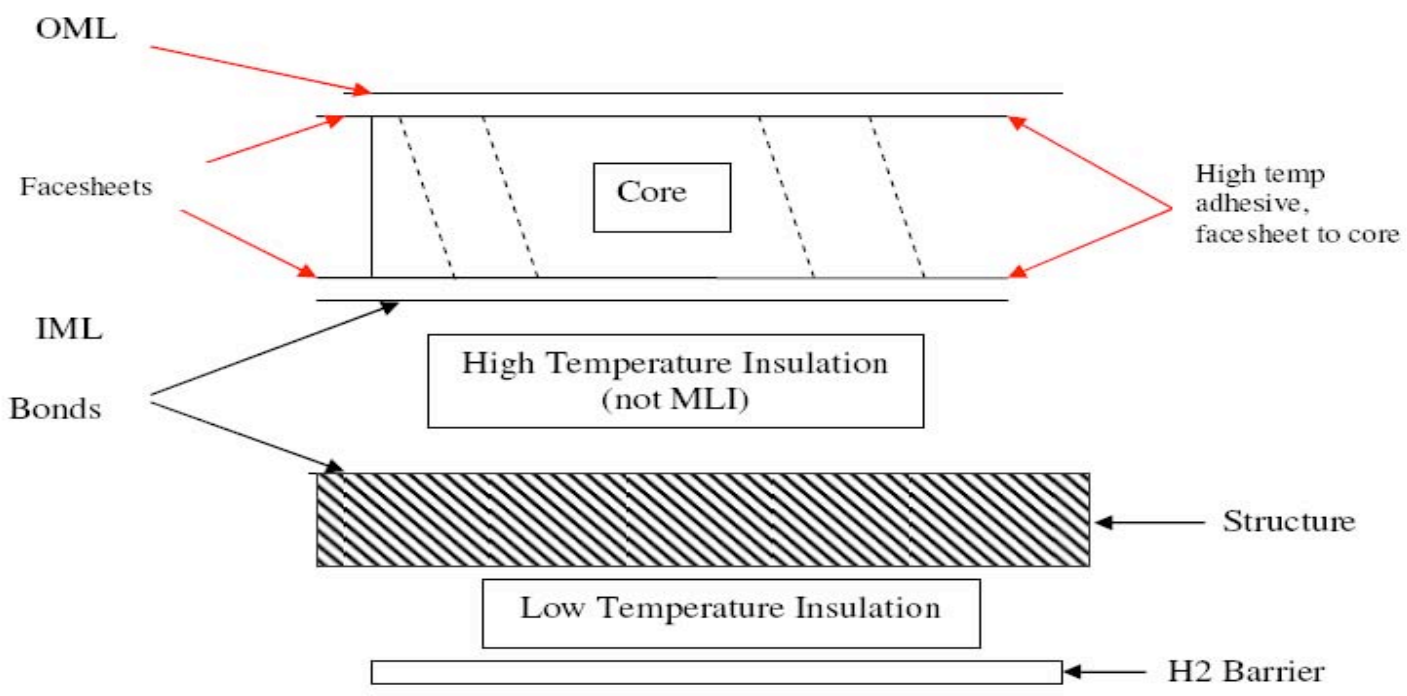

Figure 8. Schematic of concept 2 (without purge gap or standoff attachments). 
The rib-stiffened CMC panel assembly was considered the best design solution due to both the system's performance under the various loading conditions as well as the willingness of fabricators to manufacture these components. MR\&D was able to design a number of CMC rib-stiffened panels which met all of the design requirements provided.

As discussed previously, there is no temperature rise problem from the standoffs when the panels are attached to an Al tank. The figures above correspond with an Al-Li tank and therefore the Z-standoffs would be fastened directly onto the tank surface, as shown in Figure 9.

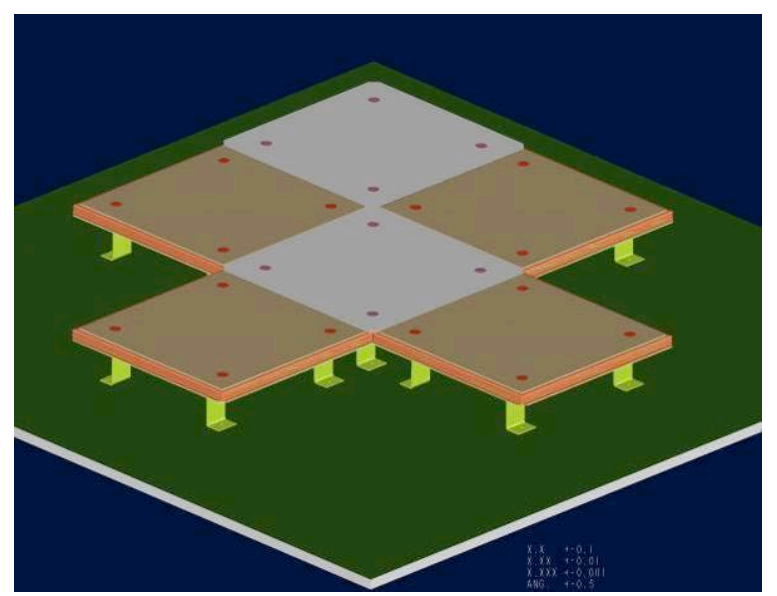

Figure 9. CMC TPS panel assembly attached directly to an Al-Li tank.

\section{E. High-Temperature Seals ${ }^{7}$}

The objective of the High Temperature Seals task was the development of dynamic seals with a reuse temperature close to $3000^{\circ} \mathrm{F}$. These seals are primarily for control surfaces that can reach temperatures near $3000^{\circ} \mathrm{F}$. NASA Glenn Research Center (NASA-GRC) was the only contractor selected for this task. Two different families of seal designs were considered for this application: ceramic wafer seals and textile-based designs (e.g., braided rope seals).

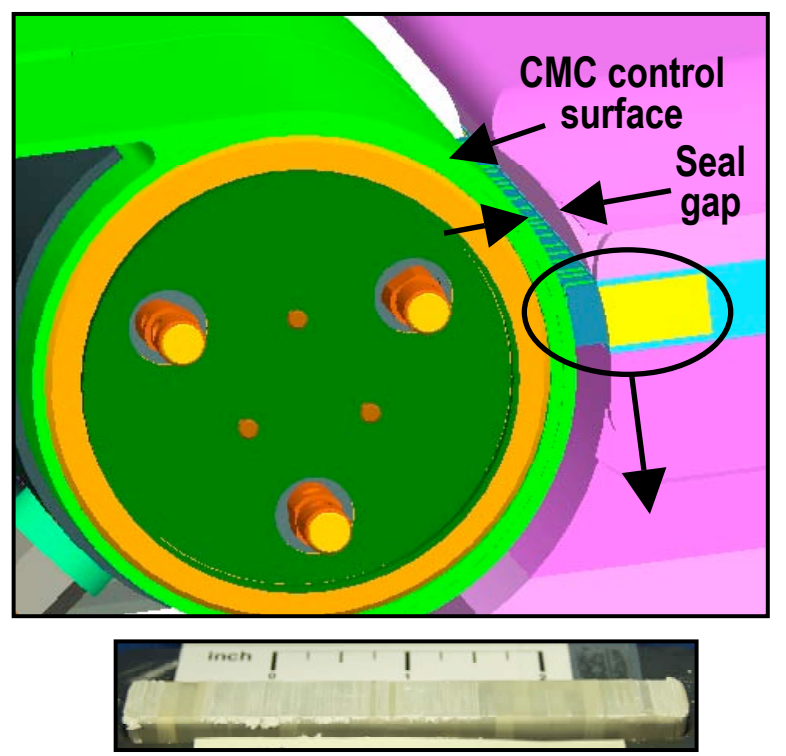

Figure 10. Seal approach with wafer seals sealing against control surface.

The seal design requirements for this application are very demanding. The seals must restrict the flow of hot gases at extreme temperatures. They must also seal against distorted, curved surfaces while not applying excessive loads to those surfaces. The seals must remain resilient for multiple load and heating cycles in order to stay in 
contact with the opposing sealing surface and must be able to survive scrubbing against those rough surfaces without a large change in leakage performance. Existing seals do not meet these challenging requirements.

The ceramic wafer seals are composed of multiple "chicklets", made of $\mathrm{Si}_{3} \mathrm{~N}_{4}$ or $\mathrm{SiC}$, to provide the required flexibility (see Figure 10). To provide additional resiliency to the seals, high temperature seal preload devices are also being developed. Commercially available silicon nitride compression springs have been evaluated (see Figure 11). Coated refractory metal (e.g., titanium zirconium molybdenum (TZM)) canted coil springs, which have a nonlinear load-displacement response that can provide a nearly-constant force over a large displacement range, are also being developed.

A series of compression tests were performed to evaluate the load versus compression behavior, resiliency, and stiffness of the silicon nitride compression springs by themselves and a row of silicon nitride wafers on top of the springs. No permanent set was observed in any of these tests even at test temperatures up to $2200^{\circ} \mathrm{F}$.

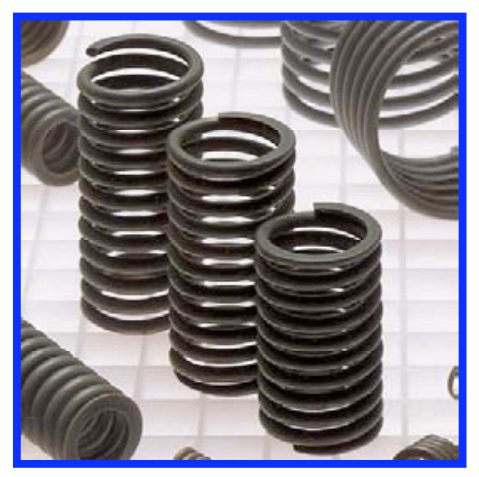

Figure 11. Silicon nitride compression springs.

High temperature scrub tests were performed in which the wafers were scrubbed against Inconel 625 rub surfaces at room temperature and $1600^{\circ} \mathrm{F}$ and against silicon carbide rub surfaces at $2000^{\circ} \mathrm{F}$ and $2200^{\circ} \mathrm{F}$. Frictional loads were lower for the tests performed against the silicon carbide rub surfaces, but there were no noticeable signs of damage on the wafers after 2000 in. of scrubbing against either type of rub surface. Flow tests performed on the wafers before and after the scrub tests showed little change in flow rates after scrubbing.

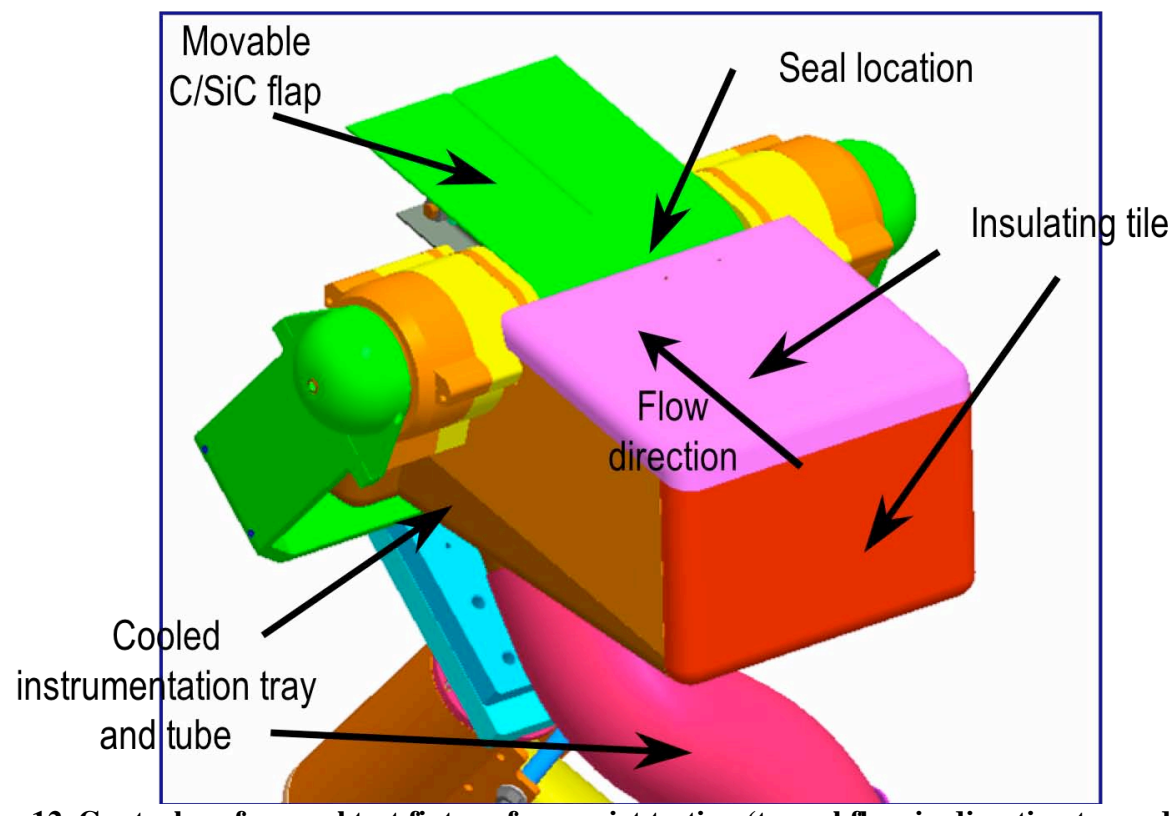

Figure 12. Control surface seal test fixture for arc-jet testing (tunnel flow in direction toward the . 
Seal testing will be performed utilizing a unique control surface test article currently under development (Figure 12). The test fixture incorporates a state-of-the-art $\mathrm{C} / \mathrm{SiC}$ control surface and permits movement of the control surface during testing. In addition, it provides the ability to test diverse seal shapes and sizes.

Results for the seal development look promising. The durability of the silicon nitride wafer seals has been demonstrated in scrub tests, and flow rates recorded for these seals before and after scrubbing were lower than those for the best textile-based seals. Silicon nitride compression springs continue to show promise as high temperature seal preload devices. The design of a new seal arc jet test fixture has been completed and fabrication is about to begin. However, further definition of seal temperatures and other requirements are needed to guide the final materials selection for the seals and preload devices.

\section{Concluding Remarks}

The Falcon MIPT has funded technology development in five different technical areas: 1) $3000^{\circ} \mathrm{F} \mathrm{C}-\mathrm{C}$ leading edges, 2) $3600^{\circ} \mathrm{F}$ refractory composite materials, 3) high temperature multi-layer insulation, 4) acreage TPS, and 5) high-temperature seals. Significant progress has been made and some of the technology will hopefully be verified on upcoming flight tests.

\section{Acknowledgments}

The work presented here was taken from the final reports of numerous researchers who performed significant work under contract to UDRI. Without their hard work, this effort could not have been accomplished. The funding and support of DARPA has enabled this technology development and is greatly appreciated.

\section{References}

${ }^{1}$ James Thompson, "Final Report, $3000^{\circ} \mathrm{F}$ Carbon-Carbon Materials for Falcon Leading Edges," Carbon-Carbon Advanced Technologies, Inc., Fort Worth, TX, March 2006.

${ }^{2}$ Richard E. Anderson, "Silicon Nitride $\left(\mathrm{Si}_{3} \mathrm{~N}_{4}\right)$ Coating On Carbon-Carbon $(\mathrm{C}-\mathrm{C})$ For $3000^{\circ} \mathrm{F}$ Hypersonic Applications Program", Final Report and Data Package, LS 931-1, United Technologies Corporation Pratt \& Whitney Rocketdyne, 31 March 2006.

${ }^{3}$ James R. Hodgson, John Shigley, and Allan Thompson, "FINAL REPORT $-3600^{\circ} \mathrm{F}$ Refractory Composite Materials for Leading Edges for Enhanced Common Aero Vehicle and Hypersonic Cruise Vehicles,” TR17316, ATK Thiokol, Brigham City, UT, 31 March 2006.

${ }^{4}$ Edward L. "Ted" Paquette, "Multi-Layer Foil Insulation Technology", Final Report, Contract RSC04020, Refractory Composites, Inc., Glen Burnie, MD, 22 March 2006.

${ }^{5}$ Steve Miller, "High Temperature Multi-Layer Insulation Development," Final Technical Report, UDRI Contract No. RSC04019, S.D. Miller \& Associates Research Foundation (SMARF), Flagstaff, AZ, 29 March 2006.

${ }^{6}$ Kerry Dunfey, Leslie J. Weller, and Brian J. Sullivan, "Hot Aeroshell to Cool Internal Structure Attachment Design," Final Report for UDRI Subcontract No. RSC04018, Materials Research \& Design, Inc., Wayne, PA, 1 September 2004 to 30 September 2005.

${ }^{7}$ Patrick H. Dunlap, Jr., Bruce M. Steinetz, and Jeffrey J. DeMange, “Application of Ceramic Seals for Future Hypersonic Vehicles," 29th Annual Conference on Composites, Materials, and Structures, Cape Canaveral/Cocoa Beach, FL, January 24-27, 2005. 